\title{
Komunikasi Interaktif Nikon Ambassador Dalam Mempertahankan Citra Merek (Studi Kasus Akun Media Sosial Instagram @Sukiminthio)
}

\author{
Ignacia Ardelia, Gregorius Genep Sukendro \\ ignacia.915160186@stu.untar.ac.id,geneps@fikom.untar.ac.id \\ Fakultas Ilmu Komunikasi Universitas Tarumanagara
}

\begin{abstract}
In today's digital era, marketing communication activities are supported by the presence of social media. Social media, one of which is Instagram, allows users to get additional information about a brand through contents uploaded by Brand Ambassadors. Brand Ambassador as a bridge of communication between brands and users, is one important factor in maintaining a positive image of a brand. This study aims to find out how interactive communication is carried out by Nikon Ambassador's Sukimin Thio on Instagram. This research uses descriptive qualitative approach and case study method. Instagram is very suitable as Nikon marketing communication media that target Millenials (young people), besides that interactive communication carried out by Sukimin as Nikon Ambassador plays an important role in maintaining a positive brand image. Sukimin's interactive communication is done every day by replying to each comment, Direct Message, presenting content that is liked by followers, and utilizing the features found on Instagram to the fullest. The conclusion from the results of this study is through interactive communication, the public become more convinced that Nikon is a good product and get comfort in discussing Nikon products. Sukimin's image as someone inspiring and fun on social media and also his youthful personality is the same as the image that Nikon Indonesia wants to form. With the presence of Nikon Ambassador helping Nikon Indonesia to increase credibility, selling points, as well as maintaining a positive image.
\end{abstract}

Keywords: brand ambassador, brand image, instagram, interactive communication.

\begin{abstract}
Abstrak
Di era digital saat ini, kegiatan komunikasi pemasaran didukung oleh hadirnya media sosial. Media sosial salah satunya Instagram memungkinkan pengguna untuk mendapatkan informasi tambahan mengenai suatu merek melalui konten yang diunggah oleh para Brand Ambassador. Brand Ambassador sebagai jembatan komunikasi antara merek dan pengguna, menjadi salah satu faktor penting dalam mempertahankan citra positif sebuah merek. Penelitian ini bertujuan untuk mengetahui bagaimana komunikasi interaktif yang dilakukan oleh Nikon Ambassador Sukimin Thio di Instagram. Penelitian ini menggunakan pendekatan kualitatif deskriptif dan metode studi kasus. Instagram sangat cocok sebagai media komunikasi pemasaran Nikon yang targetnya Millenials (anak muda), selain itu komunikasi interaktif yang dilakukan Sukimin sebagai Nikon Ambassador berperan penting dalam mempertahankan citra positif merek. Komunikasi interaktif dilakukan Sukimin setiap hari dengan cara membalas tiap-tiap komentar, Direct Message, menyajikan konten yang disukai pengikut, serta memanfaatkan fitur yang terdapat pada Instagram secara maksimal. Simpulan dari hasil penelitian ini adalah melalui komunikasi interaktif khalayak menjadi lebih yakin bahwa Nikon adalah produk yang bagus dan mendapatkan kenyamanan dalam berdiskusi mengenai produk Nikon. Citra Sukimin sebagai seseorang menginspirasi dan menyenangkan di media sosial serta kepribadiannya yang anak muda sama seperti citra yang ingin dibentuk Nikon Indonesia.
\end{abstract}


Dengan adanya Nikon Ambassador membantu Nikon Indonesia untuk meningkatkan kredibilitas, nilai jual, juga mempertahankan citra yang positif.

Kata Kunci: brand ambassador, citra merek, instagram, komunikasi interaktif.

\section{Pendahuluan}

Di era digital saat ini, komunikasi pemasaran telah memasuki babak baru dimana semua kegiatan komunikasi pemasaran dapat dilakukan dengan memanfaatkan berbagai media yang ada di internet. Jumlah pengguna internet yang terus bertambah tiap tahunnya kemudian dimanfaatkan dalam bidang komunikasi pemasaran dengan biaya promosi rendah namun dengan pencapaian luar biasa.

Perkembangan teknologi internet telah mengubah berbagai aspek kehidupan termasuk perilaku dan juga minat beli konsumen. Tren berubah, sekarang pengguna media sosial tidak hanya mencari informatif tentang produk atau jasa, namun lebih memperhatikan personality serta value yang akan didapat dari akun yang diikuti di media sosial.

Media baru (new media) merupakan istilah yang digunakan untuk menggambarkan perkembangan media saat ini. Media baru memiliki kekuatan dalam penguasaan teknologi Internet yang mempunyai dampak positif bagi masyarakat dan membawa perubahan. Digitalisasi dan konvergensi semua aspek media menjadi identitas awal dari new media, selain itu sifat yang semakin interaktif antar anggota jejaring menjadi hal penting. Media baru mengajak siapa saja yang tertarik untuk memberikan kontribusi dan umpan balik (feedback) secara terbuka, memberi komentar, serta berbagi informasi dalam waktu cepat dan tak terbatas. Seiring perkembangan zaman, banyak jenis-jenis media baru yang bermunculan di masyarakat (Rusdi dan Sukendro, 2018). Salah satunya adalah Instagram.

Faktanya, Instagram, media sosial yang populer dan banyak digunakan di Indonesia, digunakan sebagai alat dan media komunikasi pemasaran. Instagram menjadi media sosial yang paling diminati oleh masyarakat umum karena di dalamnya berisi berbagai konten foto dan video yang bervariatif, salah satunya konten fotografi. Pada dasarnya Instagram merupakan photo sharing platform sehingga sangat cocok sebagai media komunikasi pemasaran produk fotografi. Instagram menjadi media sosial pendongkrak eksistensi paling tinggi di kalangan anak muda (Saufika, 2012).

Cara baru komunikasi pemasaran yang populer digunakan oleh pelaku bisnis saat ini adalah komunikasi interaktif melalui media sosial. Proses pemasaran secara interaktif merupakan sebuah langkah pemasaran yang memungkinkan adanya keterkaitan yang lebih signifikan antara merek dengan konsumen (Kotler dan Keller, 2012).

Pemasaran interaktif merupakan kegiatan komunikasi dan program online jangka panjang yang dirancang untuk melibatkan pelanggan secara langsung maupun tidak, meningkatkan kesadaran, mempertahankan dan memperbaiki citra, dan atau menciptakan penjualan produk dan jasa (Kotler dan Keller, 2009). Komunikasi interaktif menjadi bauran komunikasi pemasaran yang paling sesuai dengan karakteristik media sosial. Komunikasi interaktif didasari pada internet yaitu salah satu ciri internet bersifat interaktif (McQuail, 2011).

The Word Pro (TWP) Inc. menunjukkan bahwa 81 persen orang terpengaruh oleh apapun yang diunggah di media sosial dan 71 persen persepsi orang meningkat terhadap sebuah merek ketika ada ulasan positif merek tersebut di media sosial. Selain 
itu 81 persen pemasar meyakini bahwa komunikasi interaktif tercatat efektif dan 78 persen merek meningkatkan konten mereka sejak dua tahun terakhir. Salah satu figur yang dapat mempengaruhi pengikutnya adalah seorang Brand Ambassador. Media sosial memungkinkan pengguna untuk mendapatkan informasi tambahan mengenai suatu merek melalui konten yang diunggah oleh Brand Ambassador. Brand Ambassador merupakan seseorang yang mempresentasikan potret atau citra terbaik sebuah produk atas suatu perusahaan (Prawira, 2012). Brand Ambassador merupakan jembatan komunikasi antara merek dan pengguna, menjadi salah satu faktor penting dalam mempertahankan citra positif sebuah merek.

Penelitian ini akan membahas Sukimin Thio, yang merupakan Brand Ambassador untuk produk kamera Nikon. Nikon Indonesia berfokus pada Instagram sebagai media komunikasi pemasaran melalui Nikon Ambassador. Sukimin Thio, merupakan salah satu Nikon Ambassador yang paling aktif dalam melakukan komunikasi interaktif.

Berdasarkan latar belakang yang telah dipaparkan diatas maka rumusan masalah dalam penelitian ini adalah bagaimana komunikasi interaktif yang dilakukan Nikon Ambassador Sukimin Thio dalam rangka mempertahankan citra merek pada media sosial Instagram? Tujuan penelitian adalah untuk mengetahui komunikasi interaktif yang dilakukan Nikon Ambassador Sukimin Thio dalam rangka mempertahankan citra merek pada media sosial Instagram.

\section{Metode Penelitian}

Pendekatan yang digunakan penulis dalam penelitian ini adalah pendekatan kualitatif yang bersifat deskriptif. Pendekatan kualitatif dipergunakan untuk menemukan atau mengembangkan teori yang sudah ada dan kemudian menjelaskan realitas dengan menggunakan penjelasan deskriptif dalam bentuk kalimat (Pujileksono, 2015). Metode penelitian yang digunakan adalah studi kasus. Studi kasus adalah penelitian yang digunakan terhadap suatu objek, yang disebut sebagai kasus, yang dilakukan secara menyeluruh dan mendalam dengan menggunakan berbagai macam sumber data (Creswell, 2010). Tipe deskriptif yang digunakan oleh penulis yaitu untuk mendeskripsikan fenomena yang terjadi pada kehidupan nyata. Studi kasus dilakukan terhadap akun Instagram @ Sukiminthio.

Subyek penelitian adalah individu atau benda yang menjadi sumber informasi data penelitian. Subyek yang digunakan penulis adalah pemilik akun@Sukiminthio yakni Sukimin Thio yang merupakan Brand Ambassador Nikon Indonesia. Obyek merupakan apa yang menjadi sasaran penelitian. Obyek penelitian yang digunakan penulis adalah media sosial Instagram akun @ Sukiminthio sebagai media interaktif yang digunakan @Sukiminthio.

Penulis menggunakan beberapa metode pengumpulan data yaitu wawancara, observasi, dokumentasi, dan studi kepustakaan. Metode pengumpulan data merupakan suatu hal yang penting dalam penelitian, karena merupakan strategi untuk mendapatkan data yang diperlukan (Basrowi dan Suwandi, 2008). Teknik analisis data yang digunakan dalam penelitian ini adalah teknik analisis data kualitatif Miles dan Huberman (Sugiyono, 2016), yang terdiri dari pengumpulan data, reduksi data, penyajian data, dan penarikan kesimpulan.

Salah satu teknik untuk menguji keabsahan data adalah dengan metode triangulasi. Triangulasi adalah pengecekan data dari berbagai sumber dengan berbagai cara dan berbagai waktu (Bungin, 2011). Penulis melakukan triangulasi sumber data, 
yaitu dengan membandingkan data hasil pengamatan dengan hasil wawancara dan membandingkan kenyataan yang dikatakan PR ahli (Suharjo Nugroho) dan Marketing Manager Nikon Indonesia (Danu Sagoro) tentang situasi penelitian. Wawancara kemudian dilakukan secara langsung.

\section{Hasil Temuan dan Diskusi}

Menurut Kotler dan Keller (2009), pemasaran interaktif merupakan kegiatan komunikasi dan program online yang dirancang untuk interaksi jangka panjang, melibatkan pelanggan secara langsung maupun tidak, meningkatkan kesadaran, mempertahankan dan memperbaiki citra, dan atau menciptakan penjualan produk dan jasa. Yang menjadi fokus dalam penelitian ini adalah komunikasi interaktif (yang dilakukan seorang Brand Ambassador) dalam mempertahankan citra merek, yang adalah Sukimin Thio sebagai Nikon Ambassador sejak 2016.

Komunikasi interaktif yang dilakukan oleh @Sukiminthio adalah dengan menghabiskan waktu beberapa jam dalam sehari setiap harinya untuk berinteraksi dengan para pengikut melalui Comment, Direct Message, dan IGStory (Polling dan Qna). Hampir setiap komentar para pengikut pada konten yang diunggahnya selalu terbalas. Ia selalu membubuhkan tanda suka (Like) pada setiap komentar yang masuk. Fitur-fitur lain yang dimanfaatkan secara maksimal antara lain fitur Hashtag, IGInsight, dan juga IGTV. Dengan ratusan ribu pengikut yang dimiliki, tak jarang konten yang diunggah mencapai ratusan komentar. Menurut Sukimin, ketika melakukan komunikasi interaktif di Instagram sama pentingnya dengan komunikasi di kehidupan nyata.

Gambar 1. Komunikasi Interaktif melalui Fitur Comment pada Akun @Sukiminthio

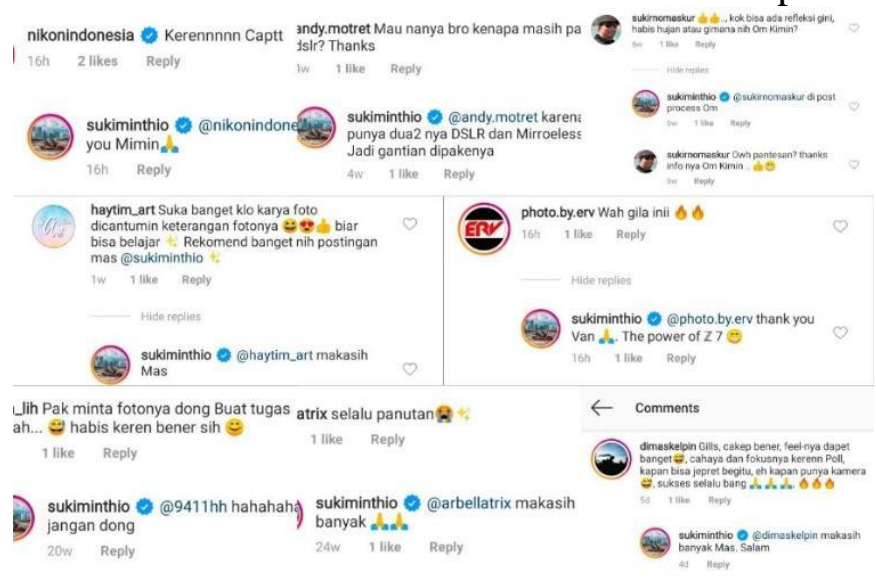

Sumber: Dokumentasi Peneliti (2019) 
Gambar 2. Komunikasi Interaktif melalui Fitur Qna pada Akun @ Sukiminthio

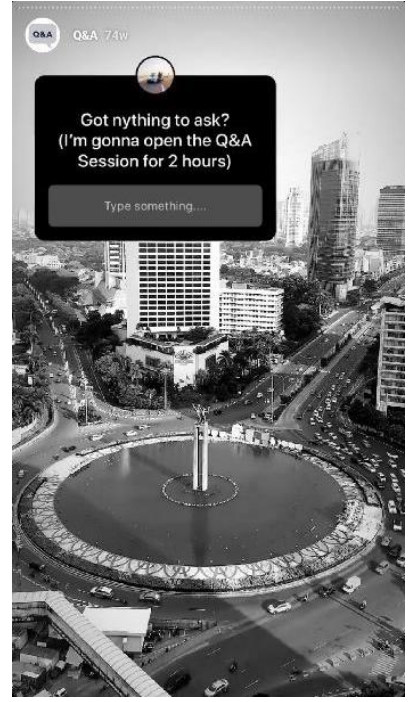

Sumber: Dokumentasi Peneliti (2019)

Sukimin menjelaskan bahwa ia mendapatkan jumlah komentar dan Likes terbanyak ketika menggunggah konten yang tidak terlalu menampilkan produk secara terus terang. Ia mengungkapkan strateginya yaitu dengan tetap mengunggah konten pemasaran yang menyatu dengan konten yang diunggah sehari-hari. Untuk pesan pemasaran dimasukkan ke dalam deskripsi foto (caption). Selain itu bahasa yang digunakan lebih dekat kepada khalayak dengan menanyakan situasi yang dihadapi mereka.

Walaupun menghadapi kendala, seperti sulit menentukan caption dan meluangkan waktu di tengah kesibukan pekerjaan, serta menurut PR ahli beberapa foto terdapat narasi sedangkan ada yang tidak (kurang seimbang dan konsisten), namun komunikasi interaktif yang dilakukan oleh Sukimin tetap dinilai tepat sasaran. Sebagai bukti, para pengikut memberikan umpan balik yang baik dan aktif. Jumlah haters-nya juga sangat kecil, hanya satu persen dan biasanya akun-akun palsu. Sukimin juga menjadi sumber rekomendasi seputar travelling and photography khususnya mengenai produk Nikon bagi para pengikutnya.

Sukimin sebagai seorang professional photographer mampu merepresentasikan Nikon dengan baik. Sebagai Nikon Ambassador, ia mampu menjawab pertanyaan-pertanyaan seputar brand Nikon dan fotografi dari para pengikutnya. Sukimin kerap menampilkan gear Nikon dan menyematkan (tag) akun Nikon Indonesia dalam foto-foto yang diunggahnya untuk menjual nama Nikon itu sendiri dan mempertahankan eksistensi serta citra merek. Kontennya juga dibuat sedemikian menarik.

Bagaimana menarik konsumen untuk lebih kenal dan membeli produk melalui saluran komunikasi bukanlah sesuatu yang mudah. Oleh karenanya, Brand Ambassador perlu memahami betul komunikasi interaktif. Sukimin sudah menerapkan komunikasi sejak 2015 dan ia mengatakan bahwa dalam menjadi seorang ambassador diperlukan keunikan serta konsistensi, itulah yang menjadi daya tarik dan pembeda dengan merek lain.

Sebagai pengguna Instagram, Sukimin merasa bahwa media sosial tersebut sangat cocok untuk menjangkau kaum Millenials yang merupakan target pasar Nikon. Ditambah lagi, 72 persen pengikutnya berada pada rentang usia antara 13-25 tahun yang masih terhitung anak muda. Oleh karenanya, ia sangat memanfaatkan fitur-fitur 
di dalamnya secara maksimal dan melakukan berbagai pendekatan, salah satunya dengan giveaway. Sukimin selalu memperhatikan inovasi dalam menyajikan konten agar tidak membosankan. Bahasa yang digunakan juga relatif tidak kaku, bergaya anak muda namun tetap sopan.

Gambar 3. Komunikasi Interaktif melalui Konten Giveaway pada Akun @Sukiminthio

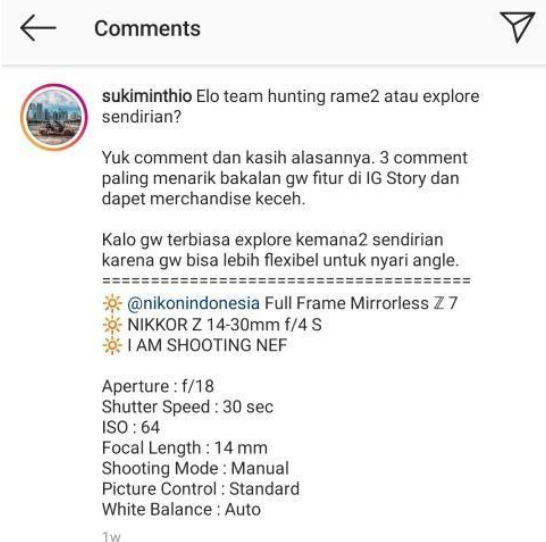

Sumber: Dokumentasi Peneliti (2019)

Nikon Ambassador mempromosikan merek terkait dengan lebih autentik dan relevan, dengan begitu akan lebih mudah untuk mempengaruhi pengikut mereka. Sukimin melancarkan komunikasi interaktif dengan tujuan agar membangun hubungan yang baik dengan para pengikutnya, pengikut lebih mengenal merek dan terlibat, serta pesan yang ingin disampaikan oleh merek tersampaikan dengan baik. Keuntungan yang didapat melalui kerjasama ini adalah Nikon bisa mendapatkan pengikut baru di Instagram melalui network dari para ambassador mereka. Melalui komunitas yang dimiliki oleh para ambassador juga akan meningkatkan jangkauan dan keterlibatan brand Nikon sendiri. Selain itu, Brand Ambassador sebagai seseorang menginspirasi dan menyenangkan di media sosial seperti Sukimin Thio akan membantu merek untuk meningkatkan kredibilitas dan nilai jual. Umpan balik yang diberikan dari pengikut adalah kepercayaan dan juga membentuk serta mempertahankan citra merek yang positif, dalam hal ini Nikon Indonesia.

Adapun citra positif sebuah merek sangat penting dalam menghadapi era globalisasi dan digitalisasi saat ini sebagai alat untuk mengukur optimalisasi kinerja perusahaan. Citra positif sebuah perusahaan atas merek dapat terbentuk dengan adanya keterlibatan antara merek dan pengguna dalam melakukan pertukaran informasi. Inilah yang disebut komunikasi interaktif. Hal ini sejalan dengan salah satu manfaat dalam penelitian ini yaitu untuk mengetahui kaitan antara komunikasi interaktif dan Public Relations. Kegiatan Public Relations adalah dengan menyebarkan informasi dan membangun hubungan baik dengan pengguna agar dapat membangun citra perusahaan yang positif. Hal ini dapat diwujudkan oleh perusahaan dengan memanfaatkan media sosial. Oleh karenanya, komunikasi interaktif yang dilakukan oleh Sukimin merupakan salah satu strategi komunikasi pemasaran yang berkaitan dengan kegiatan Public Relations dalam rangka mempertahankan citra positif perusahaan atas merek. 


\section{Kesimpulan}

Komunikasi interaktif dilakukan Sukimin setiap hari dengan cara membalas tiap-tiap komentar, Direct Message, konten yang diunggahnya, serta memanfaatkan fitur-fitur yang terdapat pada Instagram secara maksimal. Instagram sangat cocok sebagai media komunikasi pemasaran Nikon yang targetnya Millenials (anak muda), selain itu komunikasi interaktif yang dilakukan Sukimin sebagai Nikon Ambassador berperan penting dalam mempertahankan citra positif merek. Melalui komunikasi interaktif khalayak menjadi lebih yakin bahwa Nikon adalah produk yang bagus dan mendapatkan kenyamanan dalam berdiskusi mengenai produk Nikon lewat berbagai fitur Instagram yang dimanfaatkan oleh Sukimin Thio. Citra Sukimin sebagai seseorang menginspirasi dan menyenangkan di media sosial serta kepribadiannya yang bergaya anak muda sama seperti citra yang ingin dibentuk Nikon Indonesia. Dengan adanya Nikon Ambassador membantu Nikon Indonesia untuk meningkatkan kredibilitas, nilai jual, juga mempertahankan citra yang positif. Kegiatan komunikasi interaktif yang dilakukan oleh Sukimin merupakan salah satu strategi komunikasi pemasaran yang berkaitan dengan kegiatan Public Relations dalam rangka mempertahankan citra positif perusahaan atas merek.

\section{Ucapan Terima Kasih}

Penulis mengucapkan terima kasih kepada Sukimin Thio, Danu Sagoro dan Suharjo Nugroho yang telah meluangkan waktunya untuk diwawancarai sebagai narasumber. Penulis juga ingin mengucapkan terimakasih kepada keluarga besar dosen dan karyawan Fakultas Ilmu Komunikasi Universitas Tarumanagara, serta kepada keluarga dan teman yang telah memberikan dorongan.

\section{Daftar Pustaka}

Basrowi \& Suwandi. (2008). Memahami Penelitian Kualitatif. Jakarta: Reneka Cipta.

Bungin, Burhan. (2011). Penelitian Kualitatif. Jakarta: Kencana Prenama Media Group.

Creswell, John W. (2010). Research Design Pendekatan Kualitatif, Kuantitatif, dan Mixed. Yogyakarta: Pustaka Pelajar.

Donovan, LM. (2019). November 15, 2019. Social Marketing Statistics to Motivate you to Market Your Business. thewordpro.com/socialmarketingstatistics-to-motivate-you-to- market-your-business/

Kotler, Philip., \& Keller, Lane Kevin. (2009). Manajemen Pemasaran. Jakarta: Erlangga.

Kotler, Philip., \& Keller, Lane Kevin. (2012). Manajemen Pemasaran. Jakarta: Erlangga.

McQuail, Denis. (2011). Teori Komunikasi Massa. Jakarta: Salemba Humanika.

Prawira Y, Mulyana S, Wirakusumah TK. (2012). Pengaruh Brand Ambassador Honda Spacy Helm-In dengan Keputusan Pembelian

Jurnal Mahasiswa Universitas Padjajaran, 1, 1, 1-14.

Pujileksono, Sugeng. (2015). Metode Penelitian Komunikasi Kualitatif.

Malang: Kelompok Intrans Publishing.

Rusdi F., Sukendro GG. (2018). Oktober 5, 2019. Analisis Industri Kreatif Dalam Memanfaatkan Identitas Kota Melalui Media Baru. Jurnal Komunikasi, 10, 1, 95-102. 
Vol. 3, No. 2, Desember 2019, Hal 365-372

Saufika A, Retnaningsih, \& Alfiasari. (2012). Gaya Hidup dan Kebiasaan Makan Mahasiswa. Jurnal Ilmu Keluarga \& Konsumen, 5, 2, 157-165.

Sugiyono. (2016). Metode Penelitian Pendidikan Pendekatan Kuantitatif, Kualitatif, dan $R \& D$. Bandung: Alfabeta. 